\title{
Assessment of Competitiveness as a Factor of Enterprise Development
}

\author{
Sekletsova O.V. \\ Department of Accounting, Analysis, Audit and Taxation \\ Kemerovo State University \\ Kemerovo, Russia \\ seklecova@list.ru
}

\author{
Comarcheva O.S. \\ Department of Marketing and Business Communications \\ Kemerovo State University \\ Kemerovo, Russia \\ Kuznecova69@list.ru
}

\begin{abstract}
In the market economy conditions, competitiveness provides efficiency of enterprise activity both within a specific market segment and current time period, and also for prospects of its existence. This criterion holistically reflects the ability of the enterprise to meet the needs of customers, effectively using available resources, it shows the conformity of products to market requirements, its qualitative and quantitative characteristics. Based on analyst estimates, the ice-cream industry in Russia will continue to grow in the medium term, and prospects of the industry will depend on the effectiveness of manufacturers marketing policy. This paper assesses the competitiveness of one of the largest entities in the regional market of ice-cream producers, as well as the main directions of improving the competitiveness of the enterprise. Basing on the comparative evaluation of competitors engaged in the production and sale of ice-cream in the local market, the competitiveness of the object under consideration is recognized as high. According to the results of the assessment, in order to improve competitiveness, recommendations are given for the development of a promotion program in the market: to strengthen the marketing component of the organization, to improve work with suppliers of raw materials (to improve product quality and reduce production costs), in addition to this, the company needs to pay attention to its financial condition.
\end{abstract}

Keywords - competition; competitiveness; SWOT analysis; ice-cream.

\section{INTRODUCTION}

Food industry is one of the industries where competition is highly developed and changes occur very quickly. Undoubtedly, one of the key factors here will be the quality of products and production processes.

No economic entity in the modern economic situation can exist and develop profitable business without taking into account the actions of competitors. Proper assessment of the company's own competitiveness, as well as formulation of a behavior strategy in the market are important factors in making various management decisions at the enterprise. Insufficient attention on the part of management to changes in the level of company competitiveness, and to other aspects of its position in the market can lead not only to a decrease in profits and worsening of the economic conditions of the enterprise, but also to a complete withdrawal from the market.

\section{ReSEARCh Methodology}

Factors of enterprise competitiveness are defined as those phenomena or processes of its production-economic activity and social-economic life of society which stimulate changes of absolute and relative size of manufacturing charges, and as a result - the level of the enterprise competitiveness.

Improvement of product quality as a fundamental component of the production competitiveness concept is necessary in the context of developing market relations and diversity of the competitive environment. The manufacturer postpones the solution of this problem under the conditions of current unstable economic situation characterized by the state distorted regulation of market relations in combination with the insufficient level of information support and low professionalism of the personnel. In addition, there is no generally accepted methodology for assessing the competitiveness of production. The existing methods do not take into account the degree of companies privatization in the industry, the psychological factor and a number of others that have a great impact on the competitiveness of production. To eliminate the shortcomings, first it is desirable to identify, systematize and rank these factors, which will increase the efficiency of assessing production competitiveness, and in turn will have a positive impact on the quality of produced goods.

Competitiveness of the enterprise synthesizes such concepts as "competitiveness of production" and "competitiveness of goods".

Despite a solid number of research works concerning the increase of products competitiveness as an important reserve of economic growth of the enterprise, competitiveness of the enterprise itself and factors affecting it are not yet sufficiently studied.

One of the problems considered in the range of increasing competitiveness issues is the issue of its evaluation, in particular quantitative. Such kind of assessment helps not only to compare the competitive 
advertising. In addition, competitors are well-known companies due to their long presence in the market.

In order to assess the products, basing on the market position of the enterprise with respect to the growth of demand for these products and the company's market share, we carried out the analysis using the BCG matrix.

LLC "Russian Cold" belongs to the companies of "dogs" type, that means it has production both with low growth rate and market share. Such companies require increased attention from management, and in case of low profitability, the company's marketing strategy should be revised.

LLC "Kemerovo Cold Storage Plant" and LLC "Grospiron" belong to the companies of "difficult children" type, that means production of the studied enterprise has a low share in the market, but at the same time high growth rate. Companies of this type require careful study, because they can later become both "stars" and "dogs".

LLC "Unilever Rus" belongs to the companies of "stars" type, that is it has a high share in the market in combination with high growth rate. Companies of this type need to be protected as much as possible and effectively controlled. These enterprises are attractive because they do not require additional investments and, as a rule, bring a stable income.

Further, the analysis of competitiveness is carried out on the basis of points system [3]. Such key factors were evaluated: product quality, financial stability of the enterprise, variety of assortment, ability of price competition, image of the company, qualification of personnel, organization of advertising, cost of deliveries, quality of management. According to experts opinion, each of the key factors in the industry is assigned a share of the factor's influence on success, for each enterprise an assessment was made on a 10-point scale, and on the basis of these estimates, the evaluating value of the factor was determined.

According to the results of the point-based estimation, competitiveness of the firms can be assessed as follows: LLC "Kemerovo Cold Storage Plant" - 8,3 points; LLC "Unilever Rus" - 8,4 points; LLC "Russian Cold" - 7,3 points; LLC "Grospiron» - 7,6 points.

LLC "Kemerovo Cold Storage Plant" loses in competitiveness only to the producer of ice-cream of "Inmarko" trademark.

The strong point of LLC "Kemerovo Cold Storage Plant" in comparison with other competitors is the quality of management. According to other indicators, the company loses though slightly to its competitors; these parameters can serve as reserves for improving competitiveness for the analyzed enterprise.

Thus, LLC "Kemerovo Cold Storage Plant" has two main competitors: LLC "Unilever Rus" and LLC "Grospiron". In this regard, further assessment of competitiveness is carried out namely in comparison with these enterprises.

A detailed analysis of the competition level in the industry on the local market was made on the basis of Michael Porter's model called "5 forces of competition" [4,5]. At the first stage of the analysis, quantitative estimates were given to the determinants by expert evaluation. At stage 2 the analysis of strengths and weaknesses of the competitive situation is carried out. 
The results of the first stage of the analysis are the following: bargaining power of suppliers is equal to 3,125 ; bargaining power of buyers is 5,0; power of existing competitors is estimated at 3,0 ; threat from new competitors is 4,18 ; threat of substitute products is 1,75 .

The overall market strength index is 3,41 , that means that the level of competition is below average. In this situation, there are many opportunities for the company in the studied region.

The strongest positive impact comes from customers it is exactly in this sphere that most of the opportunities for the enterprise are concentrated. There are no significant threats from the competitive environment - all factors are in a neutral position. The greatest threat is posed by substitute products, since ice-cream is not a product of prime necessity and has a seasonal demand. However, we should mention that at the moment the production of certain types of LLC "Kemerovo Cold Storage Plant" goods has no analogues in the local market. For example, such type of product is an icecream "Siberian Coal" - black ice-cream with a local theme. Thus, LLC "Kemerovo Cold Storage Plant" has opportunities for winning a bigger market share and strengthening its positions in the fight against possible competitors.

In order to assess the market position of LLC "Kemerovo Cold Storage Plant", SWOT-analysis was carried out [6].

At the first stage, on the basis of internal marketing audit and conducted mass survey among consumers of products, strengths and weaknesses of the enterprise were identified and analyzed.

The following strengths can be identified:

A modern enterprise of a rapidly developing industry. In addition, food industry in the region at present is supported by the promotion of local producers, fairs under the auspices of "Made in Kuzbass".

Good reputation of the enterprise. This manufacturer has existed for more than 50 years, it is characterized by stability of production, and the conducted marketing activities allow it to cover different age and other target category of consumers. It produced ice-cream called "USSR" and "GOST" for older consumers, "Shalovlyandiya" - to reach the children's audience, thematic ice-cream called "Siberian Coal", "Siberian Blue Spruce" - to the Day of the Miner.

High competence of the staff. The company's management is attentive to the issues of recruitment for key positions. There are a number of competencies that must be met by a newly hired employee in accordance with a certain position. These competencies include not only availability of higher specialized education, but also knowledge of foreign languages in the technical field (English, Chinese, German etc.) in accordance with the geography of sales.

Management's actions are aimed at training and development of personnel. It is also necessary to underline the conduct of educating business seminars, trainings for new and existing employees, which are part of the overall successfully functioning system of employee training, as well as the developed system of employee motivation.

High product quality. As in any other industry of mass production, the undoubted attribute of the success of the enterprise is the quality of produced goods. Since 2008, the quality management system, allowing to provide stable quality according to the accepted state standards and the developed specifications, has been successfully introduced and functions at the enterprise.

Modern sales system. Among other things, the company pays special attention to the functioning of Sales Department. The emphasis is made on the popularity of the brand among the owners of retail shops, the development of activities (promotions and other marketing proposals) for the possibility of selling products through chain stores.

Work on improvement of technological process. LLC "Kemerovo Cold Storage Plant" regularly carries out monitoring of technological process of production and introduces measures for its improvement. For example, in order to reduce the level of fixed costs, the production of icecream and waffles, accompanying the production of icecream, was transferred geographically to one production complex, which allowed to reduce not only fixed costs, but also transport costs.

\section{The weaknesses include the following:}

Unstable financial position and significant financial dependence on creditors. Every month, about $1 \%$ of the revenue goes to repay bank interest. Such a significant debt at the enterprise appeared as a result of a sharp jump in euro exchange rate in 2014-2015, because the main equipment was purchased earlier for leasing in foreign currency. The share of equity in the balance sheet currency is about $25 \%$, there is a shortage of own working capital for the formation of reserves.

Strong competitors, able to interest not only customers but also employees. The main competitors in the ice-cream market are "Unilever Rus" and LLC "Grospiron". There is a practice of luring key employees, it is also possible come across leak of information about production and sales technologies. In this regard, each employee of the company signs a contract on trade secrets during employment.

High costs to launch new products that may not be in demand from customers in the future. Annually LLC "Kemerovo Cold Storage Plant" introduces ten new products and takes away up to ten old versions of the products. The need for input and output of products is determined by the specific character of the industry. The modern consumer prefers new tastes and a variety of brand-new goods, and also new packing design of an old product.

Low wages of employees of the organization, insufficient economic stimulation. The wage system at the enterprise is built in such a way that even a slight decrease in production or trade indicators entails a decrease in the level of wages of employees. Due to the seasonality of the consumed products, there is an outflow of personnel in autumn and its entry in spring, since the wages of employees in winter are lower. This situation leads to additional costs, does not allow to increase the salaries of employees.

Low level of staff interest in the results of the organization. Due to the lack of additional motivation for over-fulfillment of production and trade indicators, as well as production efficiency indicators, the company's staff remains uninterested in the overall economic result of the enterprise. In addition, due to seasonal staff turnover, cases of theft and fraud are not uncommon.

Thus, the greatest threat to the company's activities represent the existing competitors.

Having studied the strengths and capabilities of the enterprise, first it is necessary to elaborate a marketing strategy for the development of the organization. Taking into consideration weaknesses and opportunities of LLC 
sum more than 10 thousand rubles, one could purchase icecream of the middle price category in the amount of 1 thousand rubles with a $50 \%$ discount. Thus, although the volume of sales increased in comparison with the same period of last year, but the average price of products has decreased significantly. This discount did not bring the expected economic effect in the form of increased profits. In this promo, the expected economic effect was not achieved because of violating the conditions of butter purchase process used in the production of ice-cream. Violation of supply contractual terms led to the inefficiency of measures to stimulate sales.

Another issue in improving the competitiveness of the enterprise due to the sales growth is to determine the breakeven point of production. The break-even point in this case is understood as the definition of the products sales volume that will ensure break-even production activity. Even if the planned costs for materials and supplies are observed and margin profit is achieved, the enterprise may not achieve the required profit as a result of the impact of fixed costs. LLC "Kemerovo Cold Storage Plant" is characterized by the big territorial dispersion of shops, presence of the outdated equipment and also by insufficient observance of the quality management system. In addition, the turnover of enterprise personnel does not allow to assess the recruited staff effectively, which causes high risks of frequent theft cases at production site. All these factors increase the size of fixed costs significantly. At the same time, the high level of equipment wearing does not allow to increase production to the maximum level, ensuring the achievement of break-even volumes. To solve these problems, new equipment was purchased, which permitted to increase production but led to financial dependence on creditors.

A positive factor for the increase in production of LLC "Kemerovo Cold Storage Plant" is the fact that ice-cream is a product of long-term storage. Besides, the enterprise has sufficient volume of own warehouses for goods storage with low cost of their maintenance, inter-shop logistics is improved, the equipment of warehouses is updated. The amount of fixed costs was reduced, while the volume of production was increased. However, the company must not stop at the achieved positive results; it is necessary to manage fixed costs on a regular basis.

Since the increase in production volumes without increasing sales volumes is economically inefficient, the following measures aimed at the pickup in sales of ice-cream in the enterprise were carried out: restructuring the ice-cream sales department; changing the motivation system of salary payment for the employees of the ice-cream sales department; conducting the measures to increase ice-cream sales in chain stores; expanding the sales geography of icecream, including sales to foreign countries; entering such markets as HORECA (sales in cafes, restaurants etc.).

\section{CONCLUSIONS}

Thus, the growth of sales volumes, as one of the main directions of increasing the enterprise competitiveness, herewith includes the simultaneous rise in profitability of production and sales.

Increasing the level of competitiveness by improving the quality of products is also one of the possible mechanisms. To control this factor, LLC "Kemerovo Cold Storage Plant" also implements the appropriate measures, namely creation of an effective quality management system: tracking of all stages of production activity, starting from the moment of purchasing raw materials and ending with the entry of finished goods into the warehouse; increase in this rise was associated with a promo for the off-season: when buying ice-cream of the "premium" category for the 
To increase competitiveness, it is recommended to productivity: creation of process maps and improvement of equipment, setup of equipment for the needs of production, education and decent salary for highly specialized personnel; prevention of theft of raw materials, parts and finished goods in the enterprise through improvement of control systems for production and warehouses; development of new receipts of products and improvement of old ones; search for new suppliers with better quality characteristics and the optimal price-quality relationship; compliance with production technology according to both state quality standards and the developed specifications.

All of the above mentioned measures have an indirect impact on such a direction of improving the products competitiveness as reduction in costs. In addition to them, for the same purposes, LLC "Kemerovo Cold Storage Plant" introduced a number of such measures as: improvement and optimization of management; improvement of payment system for engineers by correlating a bonus part of their salary with basic production and marketing records; transfer of primary production within the holding to the city of Kemerovo to reduce transport costs; debt restructuring in terms of foreign currency loans of the company.

Another effective tool for improving the competitiveness of an enterprise is benchmarking. It is defined as a systematic and permanent research combined with the study of best practices of competitors and players in related industries, involving a constant comparison of the desired results and feasible business changes with the developed reference model.

As part of the ongoing benchmarking LLC "Kemerovo Cold Storage Plant" is constantly broadening the range of products, adjusting not only to preferences of consumers, but also to the studied best practices of such a major competitor as LLC "Unilever Rus". Over the past two years, the company has introduced the production of the following goods: soft ice-cream (sold through its own points of sale); ice-cream bars (one of the most popular product in chain stores); ice cream with a unique recipe - "Siberian Coal", "Siberian Blue Spruce".

In order to take into account all the opportunities to increase competitiveness, the company needs to develop an integrated marketing strategy. Marketing strategy is developed to specify the basic strategies of the organization.

Anyway, whatever strategy the company adheres to, it must manage and be able to quickly adapt its strategy to the changing conditions of competitive fighting. While developing a strategy, it is advisable for LLC "Kemerovo Cold Storage Plant" to be guided not only by activity of competitors, but also by inquiries of consumers. It should find a balance, paying attention to the opposition to competitors and to meeting the demands of customers. develop an integrated long-term program of promotion in the market, to strengthen the marketing component of the organization, as well as to improve work with suppliers of raw materials (in order to improve product quality and reduce costs). LLC "Kemerovo Cold Storage Plant" is recommended to introduce various types of strategies for different classes of goods because the produced ice-cream has gradation from the lowest to premium class, herewith production capacities of the enterprise allow to manufacture at present a considerable amount of production of different type.

The main directions of increasing competitiveness are continuous adaptation to changing external conditions, the formation of demand for certain products, the use of innovative approaches to improve the efficiency of using labor, material, non-material and financial resources that form the competitive advantages of the enterprise.

\section{References}

[1] Business consulting and Analytics based on Big Data technology. URL: http://merku.ru/

[2] Official website of LLC "Kemerovo Cold Storage Plant". URL: http://www.morojenoe.ru/contacts/kemerovo/

[3] Postnikov V.M., Spiridonov S.B. Methods of Selecting the Weighting Factors of Local Criteria. Science and Education: Scientific Publication. 2015, 6, pp. 267-287. DOI: 10.7463 / 0615.0780334

[4] Porter M.E. Competitive strategy: Methods of analysis of industries and competitors. Michael porter; TRANS. 6th ed. Moscow: Alpina Publisher. 2016, 453. (Michael E. Porter Competitive strategy: Techniques for Analyzing Industries and Competitors. The free press. New York. 1998, 432).

[5] Porter M.E. Location, competition, and economic development: Loca clusters in a global economy. Economic development quarterly. 2000, 14(1), pp. 15-34. DOI: 10.1177 / 089124240001400105

[6] Jenster Per, Hussey David. Analysis of the company's strengths and weaknesses. Identify strategic opportunities. Moscow: Williams. 2016, 368. (Per V. Jenster, David Hussey, Company Analysis: Determining Strategic Capability. Wiley, England. 282).

[7] Christofi M., Leonidou E. and Vrontis D. Cause-related marketing, product innovation and extraordinary sustainable leadership: the root towards sustainability. Global Business and Economics Review. 2015, vol. 17, 1, pp. 93-111.

[8] Fleischer K., Bensussan B. Strategic and competitive analysis. Methods and means of competitive analysis in business. Moscow: Binom. Knowledge lab. 2017, 544. (Craig S. Fleisher, Babette E. Bensoussan Strategic And Competitive Analysis: Methods And Techniques for Analyzing Business Competition. Prentice Hall. 2002, 457)

[9] C. Stringer and R. Le Heron (eds). Agri-Food Commodity Chains and Globalising Networks (The Dynamics of Economic Space). Routledge. 2016, 258.

[10] Alexsandr S. Kuznetsov. Russian Professor's meeting. Russian Journal of Physical Education and Sport. 2019, 14(1), pp. 17-22. DOI: 10.14526/2070-4798-2019-14-1-18-24

[11] Christofi, M., Leonidou E. and Vrontis D. Cause-related marketing, product innovation and extraordinary sustainable leadership: the root towards sustainability. Global Business and Economics Review. 2015, vol. 17, 1, pp. 93-111. 